DOI 10. 18307/2018. 0618

(C) 2018 by Journal of Lake Sciences

\title{
不同出露时间下洞庭湖洲滩土壤及生态系统呼吸特征”
}

\author{
周 延 ${ }^{1,2}$, 靖 䂞 ${ }^{2,3}$,杨 萌 ${ }^{2,4}$, 史林鹭 ${ }^{2}$, 吕 偲 ${ }^{2}$, 雷光春 ${ }^{2 * *}$ \\ (1:南京林业大学南方现代林业协同创新中心生物与环境学院,南京 210037) \\ (2: 北京林业大学自然保护区学院,北京 100083) \\ (3: 中南林业科技大学林学院, 长沙 410004) \\ (4: 中国科学院地理科学与资源研究所生态系统网络观测与模拟重点实验室, 北京 100039)
}

\begin{abstract}
摘 要: 于 2015 年 1 月洞庭湖枯水期, 针对不同出露时间下的洲滩, 调查其土壤理化性质, 并利用 LI-8100 便携式二氧化 碳气体分析仪监测其生态系统呼吸. 结果表明: 在洞庭湖枯水期, 洲滩出露后, 洲滩土壤有机质、硝态氮、铵态氮和全氮含 量随出露时间增长而先升高后降低. 土壤溶解性有机碳含量是影响洞庭湖枯水期洲滩生态系统呼吸强度的最重要影响 因子. 溶解性有机碳含量随出露时间增长而提高, 洲滩生态系统呼吸强度随之提高, 并在洲滩出露约 60 天后达到最高值. 出露洲滩生态系统呼吸通量均值为 $0.72 \pm 0.55 \mu \mathrm{mol} /\left(\mathrm{m}^{2} \cdot \mathrm{s}\right)$, 超过杨树林地、芦苇地和农田地, 成为洞庭湖区冬季 $\mathrm{CO}_{2}$ 排 放最活跃的区域.
\end{abstract}

关键词: 洞庭湖; 洲滩; 退水期; 土壤;生态系统呼吸

\section{Soil properties and ecosystem respiration characterization of mudflat in Lake Dongting during drawdown period}

ZHOU Yan ${ }^{1,2}$, JING Lei ${ }^{2,3}$, YANG Meng ${ }^{2,4}$, SHI Linlu ${ }^{2}$, LV Cai ${ }^{2}$ \& LEI Guangchun ${ }^{2 * *}$

(1: Co-Innovation Center for Sustainable Forestry in Southern China, College of Biology and the Environment, Nanjing Forestry University, Nanjing 210037, P.R.China)

(2: School of Nature Conservation, Beijing Forestry University, Beijing 100083, P.R.China)

(3: School of Forestry, Central South University of Forestry and Technology, Changsha 410004, P.R. China)

(4: Key Laboratory of Ecosystem Network Observation and Modeling, Institute of Geographic Sciences and Natural Resources Research, Chinese Academy of Sciences, Beijing 100039, P.R.China)

Abstract: Soil properties from mudflat at different exposure duration level were investigated during the drawdown period of Lake Dongting in January 2015. The ecosystem respiration was also measured using LI-8100 soil $\mathrm{CO}_{2}$ flux system. After mudflat's exposing to the air, soil organic matters, soil nitrate nitrogen, soil ammonium nitrogen and soil total nitrogen contents increased at early time, then decreased. Dissolved organic carbon was the most important driving factor for the ecosystem respiration from mudflat during the drawdown period of Lake Dongting. The dissolved organic carbon value was monotonic increasing with the time of mudflat exposing to the air increasing, which strengthens ecosystem respiration from mudflat. The ecosystem respiration flux achieved peak value about 60 days after exposing to the air. The mean ecosystem respiration flux from mudflat was $0.72 \pm 0.55 \mu \mathrm{mol} /\left(\mathrm{m}^{2} \cdot \mathrm{s}\right)$, exceeding the fluxes from poplars, reeds and farmlands. The exposed mudflat became the mainly active $\mathrm{CO}_{2}$ releasing area in Lake Dongting during the drawdown period.

Keywords: Lake Dongting; mudflat; drawdown; soil; ecosystem respiration

二氧化碳 $\left(\mathrm{CO}_{2}\right)$ 作为主要温室气体之一, 对全球温室效应的贡献率将近 $60 \%{ }^{[1]}$, 在过去数十年间, 大气

* 林业公益性行业科研专项项目 (200804005) 和江苏高校优势学科建设工程项目 (PAPD) 联合资助. 2018-03-26 收 稿; 2018-05-07 收修改稿. 周延(1982 ), 男,博士;E-mail:zhouyan.eco@ foxmail.com.

** 通信作者;E-mail: leiguangchunbjfu@ gmail.com. 
$\mathrm{CO}_{2}$ 浓度的升高被认为是全球气候变暖的最主要原因 ${ }^{[2]}$. 生态系统呼吸是生态系统向大气释放 $\mathrm{CO}_{2}$ 的过程, 受多种生物因子和非生物因子影响 ${ }^{[3]}$. 水分含量可影响微生物生长及其可溶性有机物的扩散以及微生物与 代谢底物的接触, 在适宜水分含量范围内, 生态系统呼吸速率随含水量的增加而提高 ${ }^{[4]}$, 当土壤水分含量高 到限制氧气在土壤中的扩散时, 土壤呼吸速率将随土壤含水量升高而降低 ${ }^{[5]}$. 温度是控制生态系统呼吸的 主导因子之一, 温度升高将提高生物酶酶活, 进而提高微生物代谢水平, 加速有机质分解, 提高生态系统呼 吸底物浓度, 促进 $\mathrm{CO}_{2}$ 的排放 ${ }^{[6]}$. 而土壤有机质含量是生态系统呼吸的主要碳源, 对土壤中 $\mathrm{CO}_{2}$ 的排放有着 重要的影响 ${ }^{[1]}$, 其含量高低决定微生物代谢底物的多塞, 与 $\mathrm{CO}_{2}$ 排放量呈显著正相关 ${ }^{[7]}$. 在不同环境条件 下, 生态系统呼吸受哪些因素影响, 其影响强度均存在较大差异, 揭示生态系统呼吸的影响要素并加以调节 是减少温室气体排放的重要手段之一 ${ }^{[8]}$.

湿地生态系统如河流、湖泊等是 $\mathrm{CO}_{2}$ 的重要来源 ${ }^{[9-10]}$, 目前, 针对湖泊生态系统 $\mathrm{CO}_{2}$ 排放的研究取得了一 定成果,每年全球湖泊生态系统向大气排放 $1943 \mathrm{Tg} \mathrm{CO}_{2}{ }^{[11]}$, 但现有的研究多聚焦在开放水面,尤其是水体表 层的 $\mathrm{CO}_{2}$ 排放上 ${ }^{[12]}$, 或者针对湖泊不同景观、植被类型下的温室气体排放 ${ }^{[13-14]}$, 较少考虑到湖泊的水文动态对 生态系统呼吸的影响. 尤其在季节性湖泊的退水期, 湖底出露, 土壤含水量由饱和状态开始下降, 氧气含量升 高, 土壤微生物活动增强, 土壤矿化速率加快, 提高了土壤呼吸底物浓度, 导致生态系统呼吸通量的变化随之 改变 ${ }^{[5-16]}$. 在退水期,随着湖盆出露时间的延长, 土壤理化性质发生哪些变化,这些变化如何影响到生态系统 呼吸通量, 尚需加以系统研究以厘清湖泊水文动态对土壤理化性质及生态系统呼吸的具体影响 ${ }^{[17]}$.

洞庭湖是长江中下游仅有的两个大型通江湖泊之一, 月平均水位在 $20.19 \sim 30.24 \mathrm{~m}$ 间浮动,过去 50 年, 洞 庭湖每年水位波动范围约为 7 16 $\mathrm{m}^{[18]}$. 在不同时期,洞庭湖出露洲滩面积变化巨大, 当洞庭湖水位处于 $21 \mathrm{~m}$ 时,其湖底出露面积可达到 $30 \mathrm{~m}$ 高水位水面面积的 $70 \%{ }^{[19]}$. 洞庭湖枯水期如此大面积的湖底出露为泥滩, 不 可避免地引起土壤理化性质和生态系统呼吸通量的变化. 本研究在洞庭湖枯水期, 针对不同出露时间的泥滩 土壤进行调查, 监测土壤理化性质及生态系统呼吸通量, 并分析出露时间对土壤理化性质的影响, 以及生态系 统呼吸通量对上述变化的响应,为通过合理管理枯水期水位减少温室气体排放提供科学依据.

\section{1 材料与方法}

\section{1 研究区概况}

洞庭湖 $\left(28^{\circ} 44^{\prime} \sim 29^{\circ} 35^{\prime} \mathrm{N}, 111^{\circ} 53^{\prime} \sim 113^{\circ} 05^{\prime} \mathrm{E}\right.$ ) 是我国第二大淡水湖, 位于湖南省东北部, 长江中游荆江 段南岸, 湖体呈近似“U”字形. 该区域属中亚热带到北亚热带之间的过渡区域. 洞庭湖受东亚季风气候影 响, 四季分明. 多年平均温度 (1950-2012 年) 在 $16.6 \sim 17.0^{\circ} \mathrm{C}$ 之间. 年平均降水为 $1200 \sim 1400 \mathrm{~mm}$, 其中 $70 \%$ 的降水集中在 4-9 月之间. 洞庭湖每年 4 月水位开始连续上涨, 7-8 月水位达到峰值, 9 月后湖泊水位随 人湖水量减少而下降, 12 月至翌年 3 月为枯水期, 水位达到年内最低值. 洪枯水期水情悬殊, 水位变幅大, 年 均水位变幅 13 35 m, 呈现 “高水湖相, 低水河相” 的特点, 这也使得大面积的洲滩每年季节性淹水, 在冬季 枯水期, 大面积洲滩出露.

\section{2 采样方法}

1.2.1 样地设置 本研究在出露时间存在早晚差异的西洞庭湖的半边湖、打靶台、新港、谢家湾、沅江河口; 东 洞庭湖的天鹅水、小西湖、春风、红旗湖选择有代表性的枯水期洲滩, 共在距明水面 $100 \mathrm{~m}$ 范围内设置 9 个无 植被的光滩采样地 (图 1). 结合各采样地的高程和 2014-2015 年洞庭湖水位逐日数据, 当水位值低于采样 地高程值时, 认为该采样地出露, 计算截止到采样时各采样地出露天数, 其中西洞庭湖样地出露天数依据南 咀水文站逐日水位计算, 东洞庭湖样地出露天数依据城陵矶水文站逐日水位计算. 本研究在 9 个采样地共 设置 23 个采样点 (表 1). 每个样点设置 1 条 $20 \mathrm{~m}$ 长的随机样线, 在样线的首末端及中部各设置 1 个生态系 统呼吸监测采样点, 在每条样线的中部设置 1 个土样采集点.

1.2.2 生态系统呼吸测定 生态系统呼吸测定采用 LI-8100(LI-COR, Lincoln, NE, USA) 便携式二氧化碳气体 分析仪. 各样点每个重复均在地表至少提前 2 3 天放置 PVC 管 (直径 $20 \mathrm{~cm}$ 、高度 $15 \mathrm{~cm}$ ), 避免对监测的干 扰, 每个 PVC 管露出地面高度约为 $2 \sim 3 \mathrm{~cm}$. 监测在 2015 年 1 月 14-24 日间进行. 为分析影响生态系统呼 吸通量的环境变量, 本研究采用今明仪器公司手持式数显温度计 (JM624) 测定了地表土壤温度、地下 $5 \mathrm{~cm}$ 
土壤温度 $\left(\mathrm{T}_{5}\right)$.

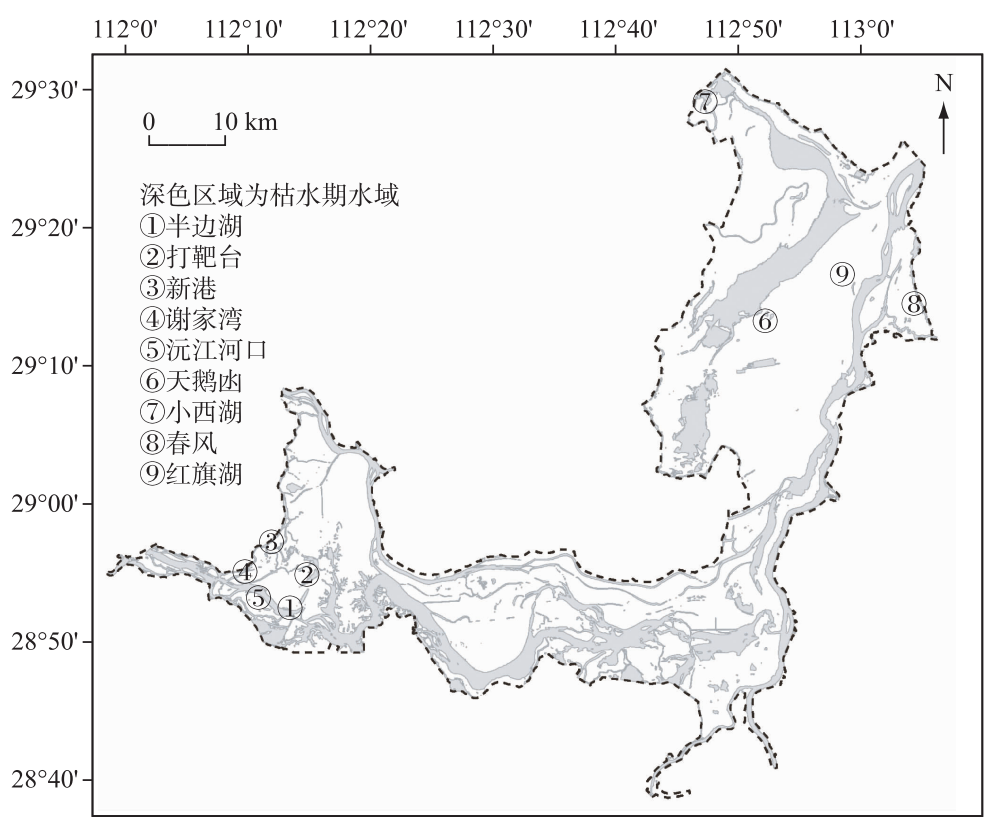

图 1 洞庭湖样地分布

Fig.1 Distribution of sampling sites in Lake Dongting

表 1 采样点设置*

Tab.1 Information of sampling points

\begin{tabular}{|c|c|c|c|c|c|c|c|c|c|}
\hline & \multicolumn{5}{|c|}{ 西洞庭湖 } & \multicolumn{4}{|c|}{ 东洞庭湖 } \\
\hline & 半边湖 & 打靶台 & 新港 & 谢家湾 & 沅江河口 & 天鹅永 & 小西湖 & 春风 & 红旗湖 \\
\hline 样点数 & 3 & 1 & 2 & 5 & 1 & 4 & 2 & 2 & 3 \\
\hline 出露时长/d & 21 & 103 & 99 & 98 & 96 & $27 / 106$ & 66 & 65 & 67 \\
\hline
\end{tabular}

* 天鹅业样地共 4 个采样点, 其中 1 个采样点出露时间为 27 天, 其余 3 个采样点出露时间为 106 天.

1.2 .3 土壤性质测定 为避免土壤采集对生态系统呼吸通量检测的干扰,土壤样品采集在生态系统呼吸监测完 成后进行. 由于洲滩土质较为松软, 使用采泥器在每个土壤采集点沿垂直方向快速下探 $30 \mathrm{~cm}$, 保证各土层之 间无扰动. 将采泥器上提后, 分别采集 $0 \sim 10 、 10 \sim 20 、 20 \sim 30 \mathrm{~cm}$ 深度土壤样品. 每层土样分为两类, 一类自然风 干, 用于分析土壤全氮 $(\mathrm{TN})$ 、有机质 $(\mathrm{SOM})$ 和溶解性有机碳 (DOC) 含量; 另一类采集后立即冷冻, 用于分析土 壤含水量 $(\mathrm{SWC})$ 、硝态氮 $\left(\mathrm{NO}_{3}^{-}-\mathrm{N}\right)$ 和铵态氮 $\left(\mathrm{NH}_{4}^{+}-\mathrm{N}\right)$ 含量. $\mathrm{NO}_{3}^{-}-\mathrm{N}$ 和 $\mathrm{NH}_{4}^{+}-\mathrm{N}$ 含量测定采用全自动智能化学分 析仪 (Smartchem 300, AMS, 意大利) ; DOC 含量测定采用有机碳分析仪( TOC-vwp, SHIMADZU, 日本) ; SOM 含 量测定采用重铬酸钾容量法; TN 含量测定采用流动注射分析仪 FIA (Star5000, FOSS, 丹麦); 测定 SWC 时, 先 称量土壤湿重 $\left(M_{0}\right)$, 然后将土壤样品烘干至恒重,称量其干重 $(M), S W C$ 计算公式为: $S W C=\left(M_{0}-M\right) / M$.

1.2.4 数据处理 所有数据分析在 SPSS 18.0 软件中进行. 未通过正态分布检验的数据采用非参数检验进行 分析. 将洲滩出露时间分为 $<30$ 天、 $\approx 60$ 天和 $>90$ 天三种类型, 采用双因素方差分析检验洲滩出露时间和土 层差异是否对土壤性质有显著影响, 使用各采样点均值绘制不同洲滩出露时间及不同土层间土壤各理化性 质和生态系统呼吸通量的柱状图. 已有研究表明: 土壤 $\mathrm{CO}_{2}$ 通量与表层土壤 $(0 \sim 10 \mathrm{~cm})$ 理化性质显著相 关 $^{[20]}$, 深层土壤 $(10 \sim 30 \mathrm{~cm})$ 理化性质对其影响较小 ${ }^{[21]}$. 因此, 本研究采用逐步回归分析表层土壤的何种理 化性质对洞庭湖生态系统呼吸通量有显著影响. 


\section{2 结果与分析}

\section{1 土壤性质}

双因素方差分析表明土层深度对 $\mathrm{SOM} 、 \mathrm{NO}_{3}^{-}-\mathrm{N}$ 和 TN 含量均有显著影响, 洲滩出露时间对 $\mathrm{SOM} 、 \mathrm{DOC} 、 \mathrm{NO}_{3}^{-}-\mathrm{N}$ 和 TN 含量均有显著影响,洲滩出露时间和土层深度的交互作用对 SOM 和 TN 含量均有显著影响(表 2).

表 2 洲滩出露时间与土层深度对土壤性质的影响

Tab.2 The impact of exposure duration (mudflat) and soil depth on soil properties

\begin{tabular}{lcccccc}
\hline & 土壤 SWC & 土壤 SOM & 土壤 DOC & 土壤 $\mathrm{NO}_{3}^{-}$-N & 土壤 $\mathrm{NH}_{4}^{+}-\mathrm{N}$ & 土壤 $\mathrm{TN}$ \\
\hline 洲滩出露时间 & $F=0.779$ & $F=10.636$ & $F=4.556$ & $F=2.320$ & $F=1.927$ & $F=20.216$ \\
& $P=0.637$ & $P<0.001$ & $P<0.001$ & $P=0.034$ & $P=0.076$ & $P<0.001$ \\
土层 & $F=0.461$ & $F=12.792$ & $F=0.157$ & $F=3.358$ & $F=0.668$ & $F=20.668$ \\
& $P=0.634$ & $P<0.001$ & $P=0.855$ & $P=0.045$ & $P=0.518$ & $P<0.001$ \\
洲滩出露时间 $\times$ & $F=1.211$ & $F=5.827$ & $F=0.824$ & $F=0.809$ & $F=0.192$ & $F=8.225$ \\
土层 & $P=0.300$ & $P<0.001$ & $P=0.663$ & $P=0.679$ & $P=1.000$ & $P<0.001$ \\
\hline
\end{tabular}

在不同深度土层中, 表层土壤的 $\mathrm{SOM} 、 \mathrm{NO}_{3}^{-}-\mathrm{N}$ 和 $\mathrm{TN}$ 含量高于深层土壤, 表层土壤 $\mathrm{NH}_{4}^{+}-\mathrm{N}$ 含量低于深层 土壤但无显著差异, 而 SWC 和 DOC 含量在不同土层间无显著差异 (图 2). 在不同出露时间下的各采样点 中, $\mathrm{SOM} 、 \mathrm{NO}_{3}^{-}-\mathrm{N}$ 和 $\mathrm{TN}$ 含量均表现出随洲滩出露时间增长而先升高后下降的显著趋势, $\mathrm{NH}_{4}^{+}-\mathrm{N}$ 含量也表现
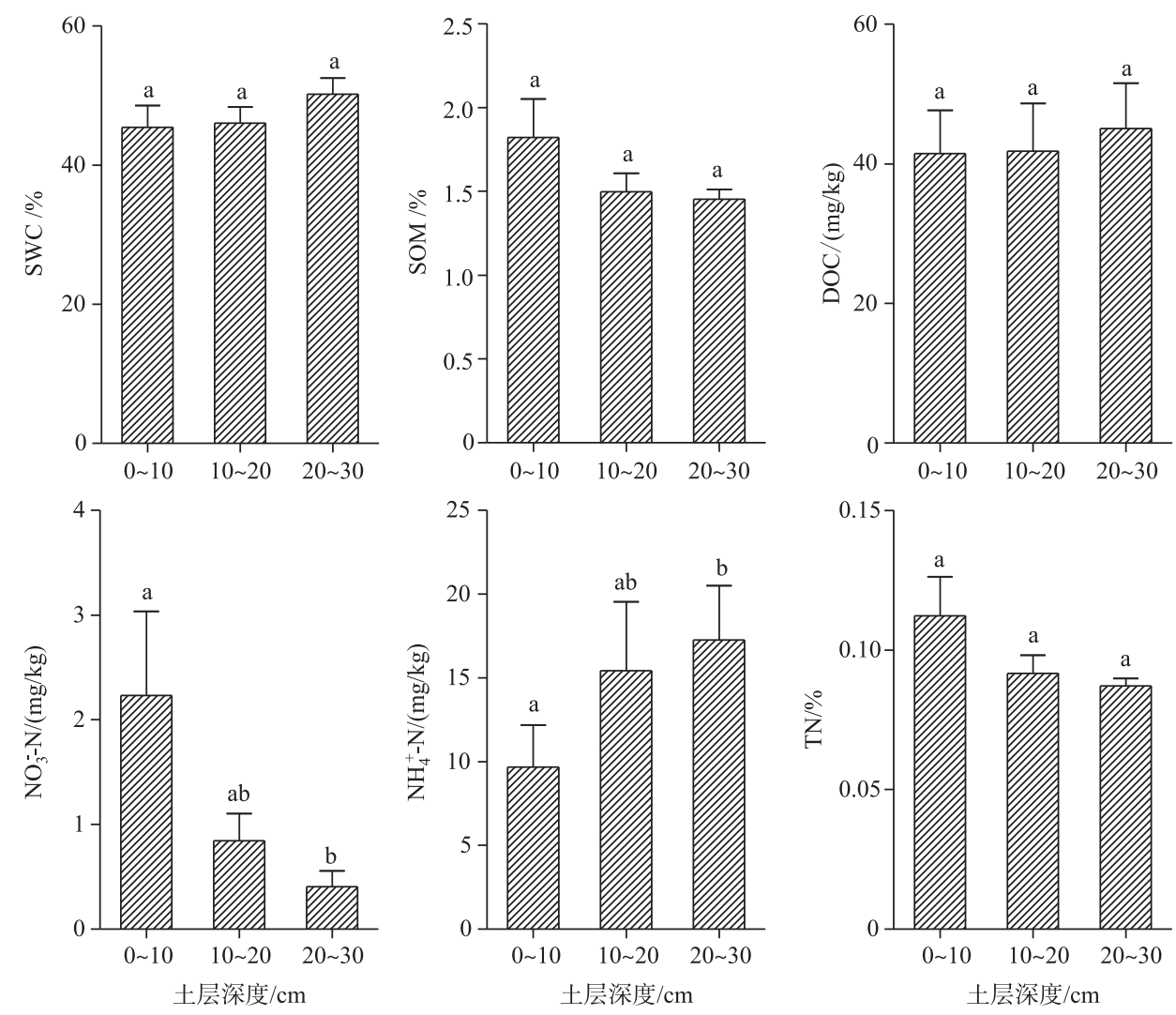

图 2 不同土层土壤性质

Fig.2 Soil properties at different soil depths 
出类似趋势, 但不显著. 洲滩出露时长为 60 天左右时, $\mathrm{SOM} 、 \mathrm{NO}_{3}^{-}-\mathrm{N} 、 \mathrm{NH}_{4}^{+}-\mathrm{N}$ 和 $\mathrm{TN}$ 含量最高. DOC 表现出随 洲滩出露时间增长而单调升高的显著趋势, SWC 含量在不同出露时间下的各采样点间无显著差异 (图 3).
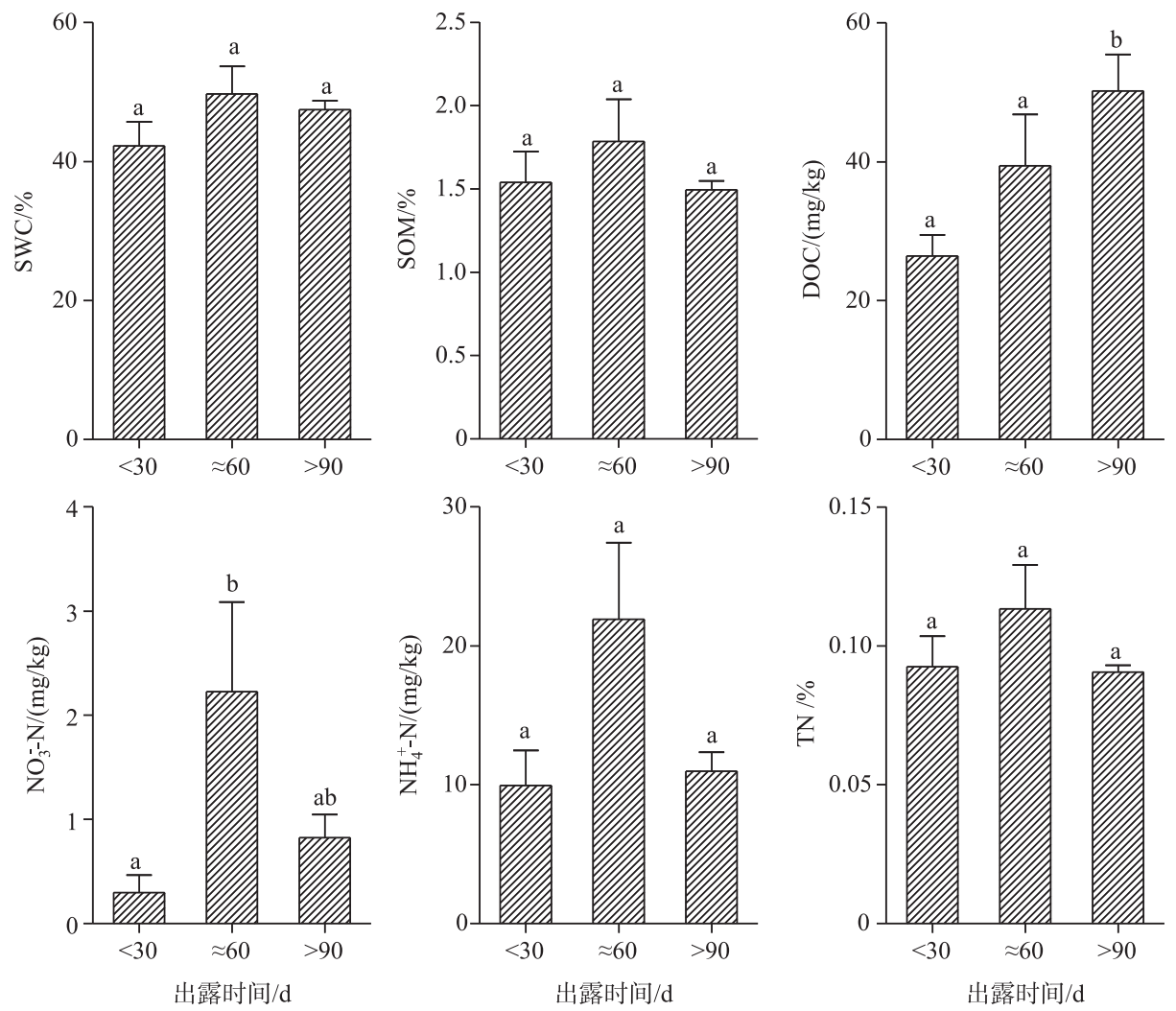

图 3 不同出露时间下土壤性质

Fig.3 Soil properties at different exposure duration levels

\section{2 生态系统呼吸}

本研究中洞庭湖出露洲滩生态系统呼吸通量均值为 $0.72 \pm 0.55 \mu \mathrm{mol} /\left(\mathrm{m}^{2} \cdot \mathrm{s}\right)$. 不同出露时间下, 洲滩生 态系统呼吸表现出随出露时间增长先升高再降低的趋势, 但无显著差异 (图 4, Kruskal-Wallis 检验, $P=$ $0.808)$.

逐步回归表明洲滩出露时间、土壤地表温度、 $\mathrm{T}_{5} 、 \mathrm{SWC} 、 \mathrm{SOM} 、 \mathrm{DOC}$ 等环境变量中只有 DOC 含量与洞庭湖 出露洲滩生态系统呼吸显著相关 ( 图 $5, y=0.010 x+0.309, N=23, R^{2}=0.280, P<0.01$ ).

\section{3 讨论}

\section{1 土壤性质}

已有研究表明, 土壤含水量是决定土壤碳含量的关键指标, 含水量越高, 土壤能够累积的碳越多 ${ }^{[22]}$. 在 本研究中, 样地所处的出露洲滩离洞庭湖枯水期明水面距离较近, 加之水位的波动, 各样地的水位较高, 土 壤含水量接近饱和, 本研究测得的 SWC 值在不同洲滩出露时间与土层深度下, 均无显著差异 (图 2,3). 各土 层间 SOM 无显著差异, 但表层土壤的 SOM 表现出高于较深层土壤 SOM 的趋势 (图 2), 这与表层土壤含水 量略低于深层土壤相悖, 说明湖泊淹水及退水过程中通过沉积作用, 对表层土壤补充外源有机物 ${ }^{[23]}$, 导致表 层土壤 SOM 偏高. 在洞庭湖区对湖盆高程进行监测, 发现近五年来洲滩年均淤积量约为 7 $8 \mathrm{~cm}$ (个人通 讯), 印证了外源有机物对表层土壤的影响, 土壤 TN 含量也由于洲滩水淹过程中的外源氮沉降, 表现出在表 
层高于深层的趋势 (图 2). 洲滩出露后, 时间越长, 表层 土壤暴露越充分, 氧气含量则越高, 继而硝化反应增 强 ${ }^{[24]}$, 使得表层土壤 $\mathrm{NO}_{3}^{-}-\mathrm{N}$ 含量显著高于深层土壤 $\mathrm{NO}_{3}^{-}-\mathrm{N}$ 含量 (图 2), 并且洲滩出露时间越长, 各层土壤 因硝化反应累计的 $\mathrm{NO}_{3}^{-}-\mathrm{N}$ 越高, 在出露时间 60 天左右 达到最高值 (图 3); 当土层较深时, 氧气含量较低, 反硝 化反应占主导地位 ${ }^{[25]}$, 表现为 $\mathrm{NH}_{4}^{+}-\mathrm{N}$ 含量在深层土壤 显著高于表层土壤 (图 2).

由于外源有机物的补充, 导致土壤的 $\mathrm{SOM} 、 \mathrm{NO}_{3}^{-}-\mathrm{N}$ 、 $\mathrm{NH}_{4}^{+}-\mathrm{N}$ 和 TN 含量与洲滩出露时间呈短期内的正相关, 而随着表层土壤产 $\mathrm{CO}_{2}$ 反应、硝化反应和反硝化反应等 活动的增强, $\mathrm{SOM} 、 \mathrm{NO}_{3}^{-}-\mathrm{N} 、 \mathrm{NH}_{4}^{+}-\mathrm{N}$ 和 $\mathrm{TN}$ 逐渐消耗 ${ }^{[26]}$, 其含量开始下降, 在较长时间尺度上, 呈负相关关系 (图 3). 此外, 随着洲滩出露, 土壤微生物代谢活动渐趋 增强, 使得土壤 DOC 含量随出露时间增长而显著增加.

\section{2 生态系统呼吸}

土壤 $\mathrm{CO}_{2}$ 的释放受土壤含水量、温度等环境变量影 响 ${ }^{[27]}$, 在本研究中, 只有 DOC 与洲滩生态系统呼吸显著 相关, 其原因在于表层土壤中溶解的有机碳为产 $\mathrm{CO}_{2}$ 反 应提供底物, 在洞庭湖枯水期, 当洲滩土壤含水量接近 饱和状态时, 碳循环过程往往受有机碳底物含量, 也就 是 DOC 调控. 在洞庭湖, 表层土壤由于暴露充分, 有利 于产 $\mathrm{CO}_{2}$ 反应, 消耗 DOC, 使得表层土壤 DOC 略低于深 层土壤 (图 2). 随洲滩出露时间增长, DOC 的消耗将引 起出露时长不同的洲滩生态系统呼吸通量差异, 但本研 究未发现出露时长与洲滩生态系统呼吸通量显著相关, 这是源于退水过程中的有机质沉积, 以及洲滩出露后土 壤微生物代谢活动的增强, 均将增加土壤 DOC 含 量 ${ }^{[28-29]}$, 在 10 20 cm 土层中, 土壤 DOC 含量随洲滩出 露时间增长而增加 (图 6), 一定程度上补充土壤生态系 统呼吸对 DOC 的消耗,使得出露早期, 土壤生态系统呼 吸底物充足, 土壤生态系统呼吸作用随之加强, 导致表 层土壤 DOC 含量在经历一段时间的上升后, 逐渐开始 下降(图 6). 因此, 洲滩出露后, 由于外源有机物累计和 土壤微生物代谢活动增强, 在出露早期, 土壤生态系统 呼吸底物随出露时间增长而增加, 生态系统呼吸强度逐 渐提高, 至出露 60 天左右达到高值, 之后由于 DOC 的持 续消耗, 土壤生态系统呼吸强度逐渐下降 (图 4).

由于洲滩出露, 土壤通气状况改善, 本研究中洞庭 湖枯水期洲滩生态系统呼吸通量均值为 $0.72 \pm 0.55$ $\mu \mathrm{mol} /\left(\mathrm{m}^{2} \cdot \mathrm{s}\right)$, 远高于相似条件下鄱阳湖水一气界面 $\mathrm{CO}_{2}$ 通量 $0.23 \mu \mathrm{mol} /\left(\mathrm{m}^{2} \cdot \mathrm{s}\right)^{[30]}$ 、太湖水一气界面 $\mathrm{CO}_{2}$ 通 量 $0.16 \mu \mathrm{mol} /\left(\mathrm{m}^{2} \cdot \mathrm{s}\right)^{[31]}$. 说明季节性湖泊在退水期, 湖底出露后, 其沉积的有机质参与产 $\mathrm{CO}_{2}$ 反应, 生态系 统呼吸强度增大, 向大气排放 $\mathrm{CO}_{2}$ 的量显著增加.

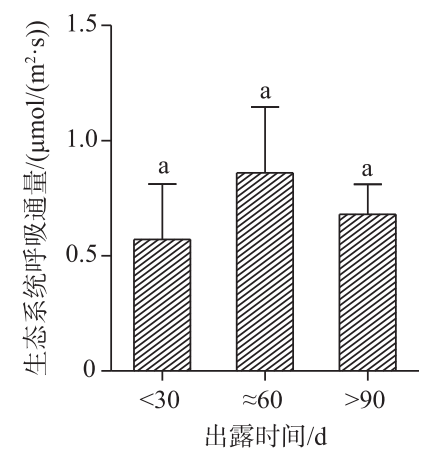

图 4 不同出露时间下洲滩生态系统呼吸通量

Fig.4 Ecosystem respiration flux from mudflat at different exposure duration level

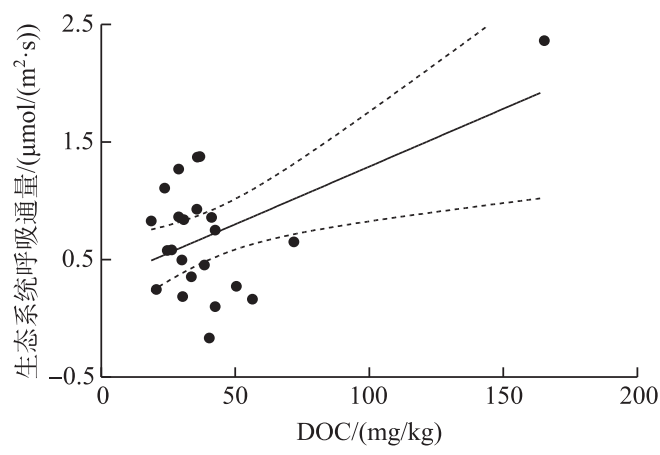

图 5 生态系统呼吸通量与 DOC 含量的关系

Fig.5 Correlation between ecosystem respiration flux and DOC content

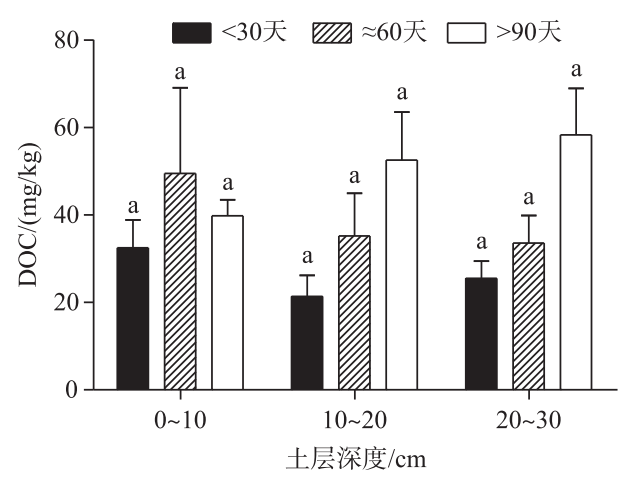

图 6 不同出露时间下, 不同土层 DOC 含量

Fig.6 Content of DOC at different exposure duration levels and soil depths 
在洞庭湖区, 洲滩地三种典型土地利用类型包括杨树林地、芦苇地和农田地, 洲滩的生态系统呼吸通量 特征与上述三种不同利用类型土地表现出相反的季节变化特征. 在非枯水期,洲滩淹没后的明水面 $\mathrm{CO}_{2}$ 通 量参考鄱阳湖、太湖监测值, 约为 $0.2 \mu \mathrm{mol} /\left(\mathrm{m}^{2} \cdot \mathrm{s}\right)$, 远低于非枯水期杨树林地 $\left(4.80 \mu \mathrm{mol} /\left(\mathrm{m}^{2} \cdot \mathrm{s}\right)\right)$ 、芦苇地 $\left(8.21 \mu \mathrm{mol} /\left(\mathrm{m}^{2} \cdot \mathrm{s}\right)\right)$ 和农田地 $\left(1.27 \mu \mathrm{mol} /\left(\mathrm{m}^{2} \cdot \mathrm{s}\right)\right)$ 的呼吸通量. 但到了枯水期,洲滩生态系统呼吸通量均 值为 $0.72 \pm 0.55 \mu \mathrm{mol} /\left(\mathrm{m}^{2} \cdot \mathrm{s}\right)$, 略高于同时期芦苇地 $\left(0.56 \mu \mathrm{mol} /\left(\mathrm{m}^{2} \cdot \mathrm{s}\right)\right)$ 和农田地 $\left(0.45 \mu \mathrm{mol} /\left(\mathrm{m}^{2} \cdot \mathrm{s}\right)\right)$, 与 杨树林地 $\left(0.70 \mu \mathrm{mol} /\left(\mathrm{m}^{2} \cdot \mathrm{s}\right)\right)$ 相近 ${ }^{[32]}$. 这说明在洞庭湖枯水期, 出露洲滩取代杨树林地、芦苇地和农田地 成为 $\mathrm{CO}_{2}$ 排放最活跃的区域. 通过人工调控减少洲滩完全出露的面积和时间有利于减少 $\mathrm{CO}_{2}$ 的排放.

致谢: 感谢湖南省西洞庭湖国家级自然保护区管理局, 湖南省东洞庭湖国家级自然保护区管理局在野外调 查工作中给予的帮助.

\section{4 参考文献}

[ 1 ] Dalal R, Allen D. Greenhouse gas fluxes from natural ecosystems. Australian Journal of Botany, 2008, 56: 396-407.

[ 2 ] Raymond PA, Hartmann J, Lauerwald R et al. Global carbon dioxide emissions from inland waters. Nature, 2013,503 : 355-359.

[ 3 ] Migliavacca M, Reichstein M, Richardson AD et al. Semiempirical modeling of abiotic and biotic factors controlling ecosystem respiration across eddy covariance sites. Global Change Biology, 2015, 17: 390-409.

[ 4 ] Sharkhuu A, Plante AF, Enkhmandal O et al. Soil and ecosystem respiration responses to grazing, watering and experimental warming chamber treatments across topographical gradients in northern Mongolia. Geoderma, 2016, 269: 91-98.

[ 5 ] Zhou Y, Li N, Grace J et al. Impact of groundwater table and Plateau Zokors (Myospalax baileyi) on ecosystem respiration in the Zoige Peatlands of China. PLoS One, 2014, 9: e115542.

[ 6 ] Andrews JJA, Matamala R, Westover KM et al. Temperature effects on the diversity of soil heterotrophs and the $\delta^{13} \mathrm{C}$ of soil-respired $\mathrm{CO}_{2}$. Soil Biology \& Biochemistry, 2000, 32: 699-706.

[ 7 ] Biederbeck VO, Janzen HH, Campbell CA et al. Labile soil organic matter as influenced by cropping practices in an arid environment. Soil Biology \& Biochemistry, 1994, 26: 1647-1656.

[ 8 ] Cui SJ, Zhu XX, Wang SP et al. Effects of warming and grazing on soil and ecosystem respirations in grassland: mini review. Guihaia, 2015, 35(1) : 126-132. [崔树娟, 朱小雪, 汪诗平等. 增温和放牧对草地土壤和生态系统呼吸的影 响. 广西植物, 2015, 35(1): 126-132.]

[ 9 ] Jeffrey LC, Maher DT, Santos IR et al. Groundwater, acid and carbon dioxide dynamics along a coastal wetland, lake and estuary continuum. Estuaries \& Coasts, 2016, 39: 1325-1344.

[10] Yang P, Tong C. Emission paths and measurement methods for greenhouse gas fluxes from freshwater ecosystems: a review. Acta Ecologica Sinica, 2015, 35(20) : 6868-6880. [杨平, 众川. 淡水水生生态系统温室气体排放的主要途径及影 响因素研究进展. 生态学报, 2015, 35(20): 6868-6880.]

[11] Williamson CE, Saros JE, Vincent WF et al. Lakes and reservoirs as sentinels, integrators, and regulators of climate change. Limnology and Oceanography, 2009, 54: 2273-2282.

[12] Ducharme-Riel V, Vachon D, Giorgio PAD et al. The relative contribution of winter under-ice and summer hypolimnetic $\mathrm{CO}_{2}$ accumulation to the annual $\mathrm{CO}_{2}$ emissions from northern lakes. Ecosystems, 2015, 18: 547-559.

[13] Liu S, Chen YW. Variations and impact factors of $\mathrm{CO}_{2}$ fluxes of Carex cinerascens-dominated and Artemisia selengensisdominated wetland in Lake Poyang during drawdown periods. J Lake Sci, 2017, 29(6) : 1412-1420. DOI: 10.18307/ 2017.0613. [刘胜, 陈宇炜. 退水期鄱阳湖菫草 (Carex cinerascens) 和藜蒿 (Artemisia selengensis) 洲滩湿地 $\mathrm{CO}_{2}$ 通量 变化及其影响因子. 湖泊科学, 2017, 29(6) : 1412-1420.]

[14] Tang J, Li ZH, Tang YX et al. Soil respiration dynamics for different land-use types on the shoreline of Lake Dongting. Journal of Zhejiang A \& F University, 2011, 28(3) : 439-443. [ 唐洁, 李志辉, 汤玉喜等. 洞庭湖区滩地不同土地利 用类型土壤呼吸动态. 浙江农林大学学报, 2011, 28(3):439-443.]

[15] Yang M, Geng XM, Grace J et al. $\mathrm{N}_{2} \mathrm{O}$ fluxes from the littoral zone of a Chinese reservoir. Biogeosciences, 2015, 12: 4711-4723.

[16] Clayton JA. Summer soil moisture loss at Utah SNOTEL sites and streamflow recession at nearby gauges: variability in runoff generation and the potential for flow forecasting. Hydrological Processes, 2016, 30: 119-134. 
[17] Hu QW, Wu Q, Yao B et al. Ecosystem respiration and its components from a Carex meadow of Poyang Lake during the drawdown period. Atmospheric Environment, 2015, 100: 124-132.

[18] Shi X, Xiao WH, Wang Y et al. Characteristics and factors of water level variations in the Lake Dongting during the recent 50 years. South-to-North Water Transfers and Water Science \& Technology, 2012, 10: 18-22.

[19] Song QM, Xiong LH, Xiao Y et al. Study on relationship between lake area and water level of Lake Dongting based on MODIS images. Water Saving Irrigation, 2011, 6: 20-23. [宋求明, 熊立华, 肖义等. 基于 MODIS 遥感影像的洞庭湖 面积与水位关系研究. 节水灌溉, $2011,6: 20-23$. ]

[20] Liu YS, Fan JW, Harris W et al. Effects of plateau pika (Ochotona curzoniae) on net ecosystem carbon exchange of grassland in the Three Rivers Headwaters region, Qinghai-Tibet, China. Plant and Soil, 2013, 366: 491-504.

[21] Luan J, Liu S, Zhu X et al. Soil carbon stocks and fluxes in a warm-temperate oak chronosequence in China. Plant and Soil, 2011, 347: 243-253.

[22] Hudson BD. Soil organic matter and available water capacity. Journal of Soil and Water Conservation, 1994, 49: 189-194.

[23] Dai SB, Yang SL, Zhu J et al. The role of Lake Dongting in regulating the sediment budget of the Yangtze River. Hydrology \& Earth System Sciences, 2005, 9: 692-698.

[24] Robinson DA, Campbell CS, Hopmans JW et al. Soil moisture measurement for ecological and hydrological watershed-scale observatories: A review. Vadose Zone Journal, 2008, 7 : 358-389.

[25] Saggar S, Jha N, Deslippe J et al. Denitrification and $\mathrm{N}_{2} \mathrm{O}: \mathrm{N}_{2}$ production in temperate grasslands: processes, measurements, modelling and mitigating negative impacts. Science of the Total Environment, 2013, 465: 173-195.

[26] Gu L, Post WM, King AW. Fast labile carbon turnover obscures sensitivity of heterotrophic respiration from soil to temperature: A model analysis. Global Biogeochemical Cycles, 2004, 18: 1022-1032.

[27] Juszczak R, Humphreys E, Acosta M et al. Ecosystem respiration in a heterogeneous temperate peatland and its sensitivity to peat temperature and water table depth. Plant and Soil, 2013, 366: 505-520.

[28] Vonk JA, Rombouts T, Schoorl JC et al. Impact of water drawdown and rewetting on sediment nutrient-dynamics in a constructed delta-lake system (Oostvaardersplassen, The Netherlands): A mesocosm study. Ecological Engineering, 2017, 108: 396-405.

[29] Liu YJ, Wu J, Zou F et al. Response of properties of soil microbes and enzymes in beach covered by Carex cinerascens in Poyang Lake Wetlands to moisture gradient. Wetland Science, 2017, 15(2) : 269-275. [刘亚军, 吴娟, 邹锋等. 鄱阳湖 湿地灰化薹草洲滩土壤微生物和酶特性对水分梯度的响应. 湿地科学, 2017, 15(2): 269-275.]

[30] Liu LX, Ming X, Mao L et al. Spatial variability of greenhouse gas effluxes and their controlling factors in the Poyang Lake in China. Polish Journal of Environmental Studies, 2013, 22 : 749-758.

[31] Xiao QT. Study on greenhouse gases $\left(\mathrm{CO}_{2}, \mathrm{CH}_{4}\right.$ and $\left.\mathrm{N}_{2} \mathrm{O}\right)$ fluxes of water-air interface in Lake Taihu [Dissertation]. Nanjing: Nanjing University of Information Science \& Technology, 2014. [肖启涛. 太湖水一气界面温室气体 $\left(\mathrm{CO}_{2}\right.$ 、 $\left.\mathrm{CH}_{4} 、 \mathrm{~N}_{2} \mathrm{O}\right)$ 通量研究 [ 学位论文]. 南京:南京信息工程大学, 2014.]

[32] Tang J. Study on soil respiration characteristics for typical land-use types on the beach land of Lake Dongting [ Dissertation]. Changsha: Central South University of Forestry and Technology, 2011. [唐洁. 洞庭湖区滩地典型土地利用类型 土壤呼吸特征的研究 [ 学位论文]. 长沙: 中南林业科技大学, 2011.] 